\title{
The Biochemical and Neuroendocrine Bases of the Hyperalgesic Nocebo Effect
}

\author{
Fabrizio Benedetti, ${ }^{1}$ Martina Amanzio, ${ }^{2}$ Sergio Vighetti, ${ }^{1}$ and Giovanni Asteggiano ${ }^{3}$ \\ ${ }^{1}$ Department of Neuroscience, University of Turin Medical School, 10125 Turin, Italy, ${ }^{2}$ Department of Psychology, University of Turin, 10124 Turin, Italy, \\ and ${ }^{3}$ Division of Neurology, S. Lazzaro Medical Center, 12051 Alba, Italy
}

\begin{abstract}
Despite the increasing research on placebos in recent times, little is known about the nocebo effect, a phenomenon that is opposite to the placebo effect and whereby expectations of symptom worsening play a crucial role. By studying experimental ischemic arm pain in healthy volunteers and by using a neuropharmacological approach, we found that verbally induced nocebo hyperalgesia was associated to hyperactivity of the hypothalamic-pituitary-adrenal (HPA) axis, as assessed by means of adrenocorticotropic hormone and cortisol plasma concentrations. Both nocebo hyperalgesia and HPA hyperactivity were antagonized by the benzodiazepine diazepam, suggesting that anxiety played a major role in these effects. The administration of the mixed cholecystokinin (CCK) type-A/B receptor antagonist proglumide blocked nocebo hyperalgesia completely but had no effect on HPA hyperactivity, which suggests a specific involvement of CCK in the hyperalgesic but not in the anxiety component of the nocebo effect. Importantly, both diazepam and proglumide did not show analgesic properties on basal pain, because they acted only on the nocebo-induced pain increase. These data indicate a close relationship between anxiety and nocebo hyperalgesia, in which the CCKergic systems play a key role in anxiety-induced hyperalgesia. These results, together with previous findings showing that placebo analgesia is mediated by endogenous opioids, suggest that the analgesic placebo/ hyperalgesic nocebo phenomenon may involve the opposite activation of endogenous opioidergic and CCKergic systems.
\end{abstract}

Key words: nocebo; placebo; pain; hypothalamus-pituitary-adrenal axis; benzodiazepines; cholecystokinin

\section{Introduction}

In recent times, the placebo effect has been analyzed with sophisticated neurobiological tools that have uncovered specific mechanisms at the biochemical, cellular, and anatomical level in different systems and conditions, such as pain, motor disorders, depression, and immune-endocrine responses (Benedetti et al., 2005; Colloca and Benedetti, 2005). It has been shown that this may occur through both expectation and conditioning mechanisms, although expectations and emotions seem to play a fundamental role (Benedetti et al., 2003; Price et al., 2005). Most of our knowledge about the placebo effect comes from the field of pain, in which both a neuropharmacological approach with opioid antagonists (Levine et al., 1978; Grevert et al., 1983; Levine and Gordon, 1984; Amanzio and Benedetti, 1999; Benedetti et al., 1999; Hoffman et al., 2005) and, more recently, brain imaging techniques (Petrovic et al., 2002, 2005; Wager et al., 2004, 2006; Zubieta et al., 2005; Keltner et al., 2006; Kong et al., 2006) have been used.

In contrast, the neurobiological mechanisms of the nocebo effect have been less investigated, despite them being interesting

Received July 12, 2006; revised Sept. 10, 2006; accepted 0ct. 11, 2006.

This work was supported by Project "Neuroscience" of the National Research Council Grants 01.00439.ST97 and 02.00529.ST97, Project "Alzheimer's disease" of the Italian Ministry of Health Grants PFA/DML/U06/2001 and PFA/ DML/U06/2001/AA, and Italian Ministry of University and Research-Fondo per gli Investimenti della Ricerca di Base Grant RBNE01SZB.

Correspondence should be addressed to Fabrizio Benedetti, Dipartimento di Neuroscienze, Università di Torino, Corso Raffaello 30, 10125 Torino, Italy. E-mail:fabrizio.benedetti@unito.it

DOI:10.1523/JNEUROSCI.2947-06.2006

Copyright $\odot 2006$ Society for Neuroscience ～0270-6474/06/2612014-09\$15.00/0 as those of the placebo effect. For example, hyperalgesia after expectation of painful stimulation is associated with changes in brain activation of different regions (Sawamoto et al., 2000; Koyama et al., 2005; Keltner et al., 2006). Expectation and/or conditioning mechanisms, which are similar and opposite to those of the placebo counterpart, are supposed to be involved (Benedetti et al., 2003). In a previous clinical study, we showed that nocebo hyperalgesia could be prevented by pretreatment with proglumide, a nonspecific cholecystokinin (CCK) antagonist for both CCK-A and CCK-B receptors, suggesting the possible involvement of CCKergic systems in the nocebo effect (Benedetti et al., 1997). However, because of ethical constraints in these patients, we did not have the possibility to investigate these effects further.

By using selective CCK-A and CCK-B receptor antagonists, several studies in animals and humans have shown the important role of CCKergic systems in the modulation of anxiety and in the link between anxiety and hyperalgesia (Hebb et al., 2005). For example, in a social-defeat model of anxiety in rats, it has been shown recently that CI-988 (4-[[2-[[3-(1H-indol-3-yl)-2-methyl-1-oxo-2 [[(tricyclo[3.3[12,17]dec-2-yloxy)-carbonyl]amino]-propyl]amino]-1phenyethyl]amino]-4-oxo-[R- $\left.\left(R^{\star}, R^{\star}\right)\right]$-butanoate $N$-methyl-Dglucamine), a selective CCK-B receptor antagonist, prevented anxiety-induced hyperalgesia, with an effect that was similar to that produced by the established anxiolytic chlordiazepoxide (Andre et al., 2005).

By taking all of these considerations into account and by considering the ethical limitations in the patients of our previous 
Table 1. Characteristics (mean \pm SD) of the subjects of each experimental group

\begin{tabular}{|c|c|c|c|c|c|c|c|}
\hline & $\operatorname{Sex}(M / F)$ & Age (years) & Weight (kg) & Basal ACTH (pg/ml) & Basal cortisol $(\mu \mathrm{g} / \mathrm{L})$ & STAI-S & STAI-T \\
\hline Group 1 & $6 / 6$ & $37.4 \pm 12.4$ & $63.1 \pm 11.5$ & $22.7 \pm 3.4$ & $106.4 \pm 8.7$ & $40.6 \pm 4.3$ & $41.1 \pm 5.9$ \\
\hline Group 2 & $6 / 7$ & $36.9 \pm 13.8$ & $62.7 \pm 13.5$ & $20.5 \pm 4.4$ & $106.5 \pm 8.9$ & $41.5 \pm 5.2$ & $40.1 \pm 4.7$ \\
\hline Group 3 & $6 / 6$ & $39.1 \pm 13.3$ & $64.0 \pm 13.1$ & $19.4 \pm 3.4$ & $103.8 \pm 7.8$ & $41.6 \pm 6.2$ & $39.2 \pm 4.7$ \\
\hline Group 4 & $5 / 7$ & $37.1 \pm 11.9$ & $66.1 \pm 14.6$ & $20.4 \pm 3.7$ & $104.8 \pm 8.3$ & $40.7 \pm 5.5$ & $40.6 \pm 5.3$ \\
\hline
\end{tabular}

M, Male; F, female.

study (Benedetti et al., 1997), we performed a detailed neuropharmacological analysis of the hyperalgesic nocebo effect in healthy volunteers by using the nonselective CCK-A and CCK-B receptor antagonist proglumide. We decided to start this pharmacological investigation of nocebo hyperalgesia because the neuropharmacological approach in humans has represented a crucial step to unravel the opioid mechanisms of placebo analgesia (Levine et al., 1978; Grevert et al., 1983; Levine and Gordon, 1984; Amanzio and Benedetti, 1999; Benedetti et al., 1999), which have subsequently been confirmed by brain imaging and in vivo receptor binding techniques (Petrovic et al., 2002; Zubieta et al., 2005).

\section{Materials and Methods}

Subjects. A total of 49 healthy volunteers participated in the study after they signed a written informed consent form in which the experimental procedure and the use of the different drugs were described in detail. Each subject underwent a complete clinical examination to rule out main diseases. To avoid high variability in hormonal responses, we adopted the following criteria. The subjects were tested with the State-Trait Anxiety Inventory (STAI) to rule out both trait and state anxiety. In the Italian population, the normal STAI-S range is $45.2 \pm 12.37$ for adult women and $40.17 \pm 10.01$ for men, whereas the STAI-T normal range is $46.1 \pm$ 11.53 for women and $39.53 \pm 9.25$ for men (Spielberg et al., 1980; Nattero et al., 1989). In our routine clinical experience, these values correspond to a range of $\sim 32-52$ for the STAI-S and $\sim 30-55$ for the STAI-T. Therefore, only subjects within these ranges were included in the study.

In addition, we decided to include only those subjects within a predetermined range of hormonal plasma concentrations. In the normal population, the range of adrenocorticotropic hormone (ACTH) plasma concentration in the morning is $\sim 10-40 \mathrm{pg} / \mathrm{ml}$, whereas the range of cortisol concentration is $\sim 80-300 \mu \mathrm{g} / \mathrm{L}$ (Liddle, 1974). To make the subjects as similar as possible, we included only those subjects who showed ACTH plasma concentration between 14 and $30 \mathrm{pg} / \mathrm{ml}$ and cortisol concentration between 90 and $130 \mu \mathrm{g} / \mathrm{L}$.

All of the experimental procedures were conducted in conformance with the policies and principles contained in the Declaration of Helsinki. The 49 subjects were randomly subdivided into four groups, whose characteristics are shown in Table 1.

Pain induction. Pain was induced experimentally by means of the tourniquet technique, according to the procedures described by Amanzio and Benedetti (1999). Briefly, the subject reclined on a bed, his or her nondominant forearm was extended vertically, and venous blood was drained by means of an Esmarch bandage. A sphygmomanometer was placed around the upper arm and inflated to a pressure of $300 \mathrm{mmHg}$. The Esmarch bandage was maintained around the forearm, which was lowered on the subject's side. After this, the subject started squeezing a hand spring exerciser 12 times while his or her arm rested on the bed. Each squeeze was timed to last $2 \mathrm{~s}$, followed by a $2 \mathrm{~s}$ rest. The force necessary to bring the handles together was $7.2 \mathrm{~kg}$. This type of ischemic pain increases over time very quickly, and the pain becomes unbearable after $\sim 14 \mathrm{~min}$ (Amanzio and Benedetti, 1999). The tourniquet test lasted $10 \mathrm{~min}$ in all subjects, who had to rate their pain intensity every minute according to a numerical rating scale, ranging from 0 (no pain) to 10 (unbearable pain).

Drugs. Diazepam (Valium; Roche, Indianapolis, IN) was given intravenously $30 \mathrm{~min}$ before the beginning of the tourniquet at a dose of 0.28 $\mathrm{mg} / \mathrm{kg}$, with an infusion rate of $0.028 \mathrm{mg} \cdot \mathrm{kg}^{-1} \cdot \mathrm{min}^{-1}$ and a total infusion time of 10 min. Likewise, proglumide (Milid; Rottapharm, Milan, Italy) was administered intravenously $30 \mathrm{~min}$ before the tourniquet at a dose of $1.5 \mathrm{mg} / \mathrm{kg}$, with an infusion time of $0.15 \mathrm{mg} \cdot \mathrm{kg}^{-1} \cdot \mathrm{min}^{-1}$ and a total infusion time of $10 \mathrm{~min}$. As shown in Figure $1 \mathrm{~A}$, proglumide is a glutamic acid-based CCK antagonist and is a nonselective antagonist that binds to both CCK-A and CCK-B receptors, or CCK-1 and CCK-2 according to the new classification (Noble et al., 1999). Note that the binding affinity, expressed as the concentration required to inhibit by $50 \%$ the specific binding of ${ }^{125} \mathrm{I}$-Bolton-Hunter CCK-8 $\left(\mathrm{IC}_{50}\right)$, is similar for CCK-A and CCK-B receptors, although it is a little bit higher for CCK-A receptors (Benedetti, 1997). The time interval from the sphygmomanometer cuff inflation (which lasted $\sim 10 \mathrm{~s}$ ) to the last squeeze was $50 \mathrm{~s}$, for a total of $1 \mathrm{~min}$ of inflation plus squeezing. Thus, the time interval from the end of drug administration to the last squeeze during the tourniquet was the same in all subjects ( $31 \mathrm{~min}$ ). By considering that the tourniquet lasted $10 \mathrm{~min}$ in all subjects, the time interval from the end of drug administration to the end of the tourniquet was $41 \mathrm{~min}$.

Experimental design. The experiments were always performed at 9:00 A.M. to avoid variability in the basal activity of the hypothalamic-pituitary-adrenal (HPA) axis, according to a randomized double-blind design in which neither the subject nor the experimenter knew what drug was being administered. To do this, either the active drug or saline solution was given. To avoid a large number of subjects, two or three additional subjects per group received an infusion of saline in place of the active drug $30 \mathrm{~min}$ before the tourniquet. These subjects were not included in the study because they were used only to allow the double-blind design, as described previously by Benedetti et al. (2003).

The complete experimental procedure is shown in Figure 1 B. Group 1 (no-treatment or natural history group; $n=12$ ) was tested twice (with an interval of $4 \mathrm{~d}$ ) with the tourniquet without receiving any treatment. Likewise, group $2(n=13)$ was tested twice, with an intertest interval of $4 \mathrm{~d}$. In the first test, these subjects did not receive any treatment, whereas in the second test, they underwent a nocebo procedure. This consisted in the oral administration of an inert talc pill $5 \mathrm{~min}$ before the tourniquet, along with the verbal suggestions that it was a powerful vasoconstrictor further increasing the tourniquet-induced ischemia. The subjects were further told that, because of the quick vasoconstriction, this would induce a faster and larger increase of pain intensity, so that a quite strong hyperalgesic effect should be expected. To further strengthen the nocebo verbal suggestions, the subjects were told that they could give up at any time. Therefore, this experimental paradigm represents a situation in which a stressor is anticipated. Group $3(n=12)$ was tested twice (intertest interval of $4 \mathrm{~d}$ ), like group 2, but these subjects received a pretreatment with diazepam 30 min before the tourniquet. Similarly, group 4 $(n=12)$ was tested with the tourniquet, like groups 2 and 3 , but 30 min after a pretreatment with proglumide.

ACTH and cortisol plasma concentration. Plasma concentrations of $\mathrm{ACTH}$ and cortisol were assessed before the tourniquet and at 5 and 10 min during the tourniquet test (Fig. 1C), according to standard clinical practice and as described previously (Rainero et al., 2001; Benedetti et al., 2003). Briefly, blood samples were collected just before and at 5 and 10 min of the tourniquet in sterile tubes and immediately centrifuged at $4^{\circ} \mathrm{C}$, and the plasma was stored at $-80^{\circ} \mathrm{C}$ until assayed. Plasma ACTH and cortisol concentrations were measured using commercially available kit [ACTH Allegro (Nichols Institute, San Juan Capistrano, CA); CORTCTK-125 (Sorin, Saluggia, Italy)]. The sensitivity of ACTH was $1 \mathrm{pg} / \mathrm{ml}$, and the intraassay and interassay coefficient of variation were 3 and $7.8 \%$. The sensitivity of cortisol was $5 \mu \mathrm{g} / \mathrm{L}$, and the intraassay and interassay 

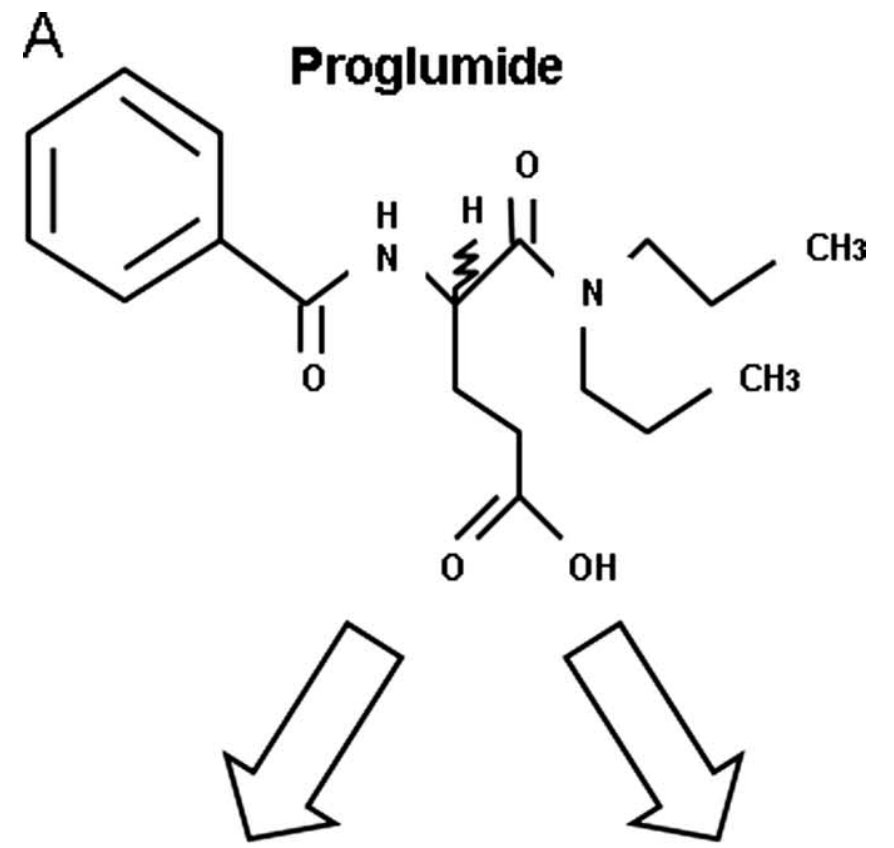

$$
\begin{aligned}
& \text { CCK-A (CCK-1) } \\
& \mathrm{IC}_{50}=6.3 \times 10^{-3} \mathrm{M}
\end{aligned}
$$$$
\text { CCK-B (CCK-2) }
$$$$
\mathrm{IC}_{50}=11 \times 10^{-3} \mathrm{M}
$$
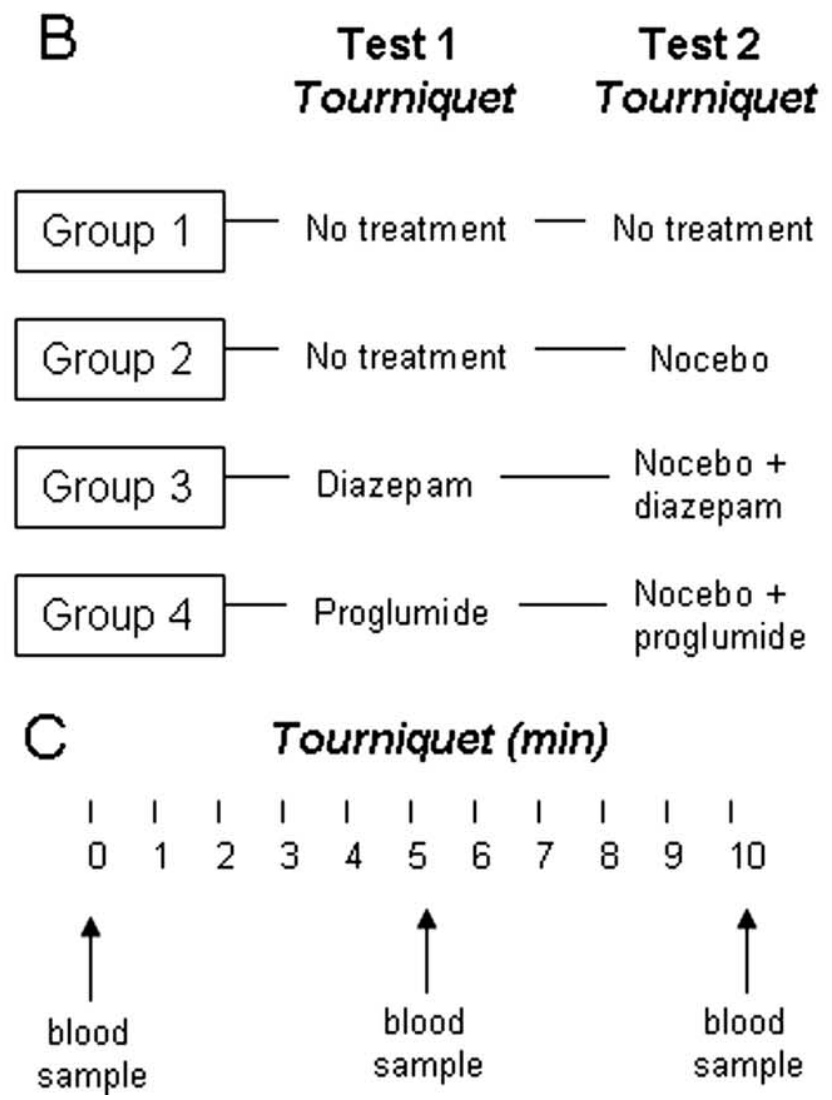

Figure 1. A, Proglumide is a nonselective CCK antagonist that binds to both CCK-A (or CCK-1) and CCK-B (or CCK-2) receptors. Note the similar binding affinity, expressed as the concentration required to inhibit by $50 \%$ the specific binding of ${ }^{125} \mathrm{I}$-Bolton-Hunter $\mathrm{CCK}-8\left(\mathrm{IC}_{50}\right)$, for CCK-A and CCK-B receptors. $\boldsymbol{B}$, Experimental design used in the present study. Each group was tested twice with tourniquet, and the interval between tests 1 and 2 was $4 \mathrm{~d}$. $\boldsymbol{C}$, Each tourniquet test lasted $10 \mathrm{~min}$, and the subjects had to rate their pain every minute while a blood sample was taken just before and at 5 and 10 min during the tourniquet. coefficients of variation were 3.8 and $5.7 \%$. All of the samples from each subject were analyzed in the same assay.

Statistical analysis. Because the experimental design involves both a between- and a within-subjects design, statistical analysis was performed by means of one-way ANOVA and ANOVA for repeated measures, followed by the post hoc Newman-Keuls test for multiple comparisons and Dunnett's test for comparisons between a control group and different experimental groups. In addition, correlations were performed by using linear regression analysis. Data are presented as mean $\pm \mathrm{SD}$, and the level of significance is $p<0.05$.

\section{Results}

As shown in Table 1, no difference was present in the four different groups, for sex, age, weight, and basal plasma concentrations of ACTH and cortisol. In addition, STAI scores for both state and trait anxiety did not differ among the groups.

The induction of ischemic pain in the no-treatment group (group 1) produced a type of pain that increased over time (Fig. $2 A$ ), along with increases in plasma concentrations of both ACTH and cortisol (Fig. 2B, $C$, respectively). It is important to note that no difference was found between the first (black circles or squares) and second (white circles or squares) tests for all of these outcome measures (pain intensity, ACTH and cortisol). Therefore, our experimental conditions were stable in the two tests, because the repetition of the experimental pain and hormonal assessment after $4 \mathrm{~d}$ did not produce different results.

In group 2, the nocebo suggestions delivered on the second test (white circles or squares) induced both a significant increase of subjective pain rating (Fig. 3A) and hyperactivity of the HPA axis, as shown by the increased plasma concentrations of ACTH and cortisol (Fig. $3 \mathrm{~B}, \mathrm{C}$ ). Pain intensity increased in both the first (black circles) and second (white circles) tests $\left(F_{(19,228)}=\right.$ $133.855 ; p<0.001)$, but the nocebo condition in the second test always induced higher pain scores compared with the first test, as assessed by the post hoc Newman-Keuls test for multiple comparisons (Fig. 3A). In fact, at the end of the 10 min test, pain rating was $5.07 \pm 0.95$ in the non-nocebo condition and $8.61 \pm 0.96$ in the nocebo condition $\left(q_{(228)}=18.304 ; p<0.001\right)$. Likewise, ACTH and cortisol increases occurred in both the first and second tests $\left(F_{(5,60)}=135.113, p<0.001\right.$ for $\mathrm{ACTH} ; F_{(5,60)}=$ $141.248, p<0.001$ for cortisol), but they were significantly larger in the nocebo condition (white squares) than in the first test (black squares), as assessed by means of the post hoc NewmanKeuls test (Fig. 3 B, C). In fact, at the end of the 10 min test, ACTH plasma concentration was $66.46 \pm 16.88 \mathrm{pg} / \mathrm{ml}$ in the nonnocebo condition and $86.69 \pm 8.45 \mathrm{pg} / \mathrm{ml}$ in the nocebo condition $\left(q_{(60)}=8.960 ; p<0.01\right)$, and cortisol was $138.2 \pm 8.38$ and $174.2 \pm 12.46 \mu \mathrm{g} / \mathrm{L}$, respectively $\left(q_{(60)}=16.671 ; p<0.001\right)$.

The administration of diazepam blocked both the noceboinduced hyperalgesia (Fig. $4 A$ ) and the nocebo-induced hyperactivity of the HPA axis (Fig. $4 B, C$ ). In fact, no difference was found between the first and the second tests, for both pain scores and hormone plasma concentrations. In contrast, proglumide only blocked the nocebo-induced hyperalgesia (Fig. $5 A$ ), but it was ineffective in reducing the nocebo-induced hyperactivity of the HPA axis (Fig. $5 B, C$ ). The plasma concentrations of both ACTH and cortisol increased in the two tests $\left(F_{(5,55)}=204.083\right.$, $p<0.001$ for ACTH; $F_{(5,55)}=147.952, p<0.001$ for cortisol), and the post hoc Newman-Keuls test showed a significantly higher hormone increase in the nocebo condition. In fact, at the end of the 10 min test, ACTH plasma concentration was $68.33 \pm$ $12.36 \mathrm{pg} / \mathrm{ml}$ in the non-nocebo condition and $87.5 \pm 6.26 \mathrm{pg} / \mathrm{ml}$ in the nocebo condition $\left(q_{(55)}=10.302 ; p<0.001\right)$, and cortisol 


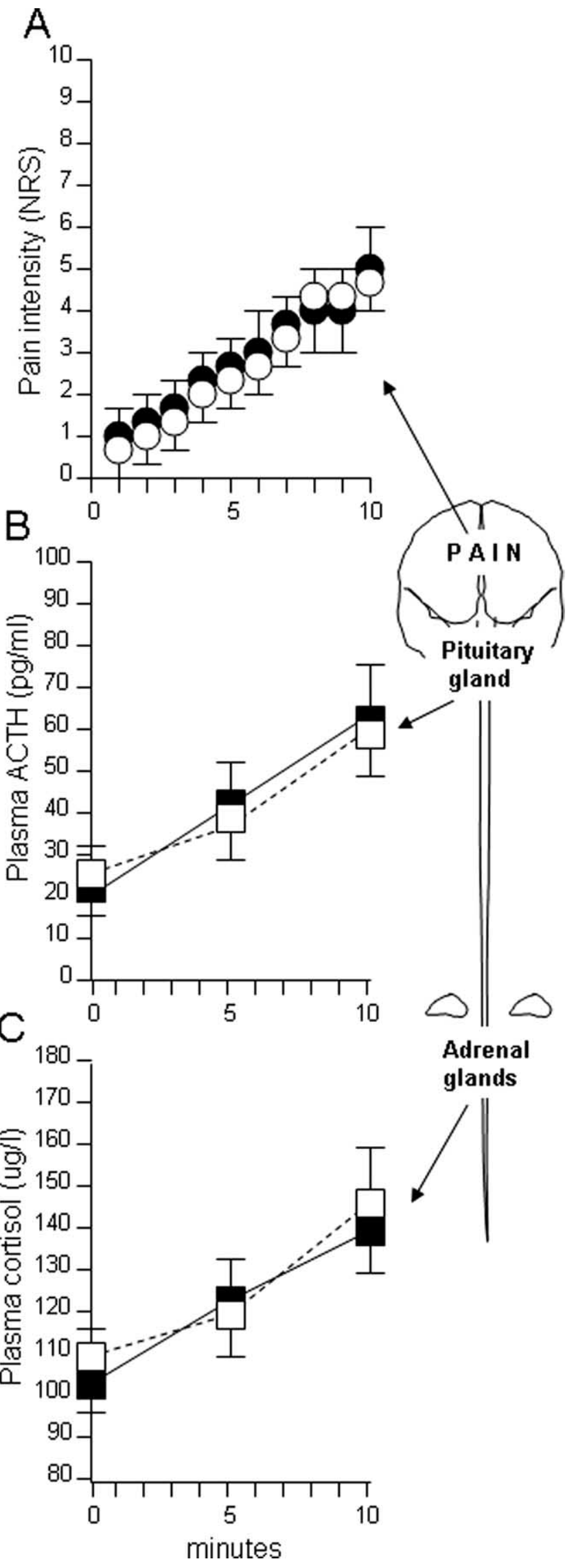

Figure 2. The natural history of pain $(\boldsymbol{A}), \mathrm{ACTH}(\boldsymbol{B})$, and cortisol ( () in test 1 (black symbols) is compared with the natural history of test 2 (white symbols). Note that no difference was present between tests 1 and 2 , indicating stable conditions of our experimental setup.

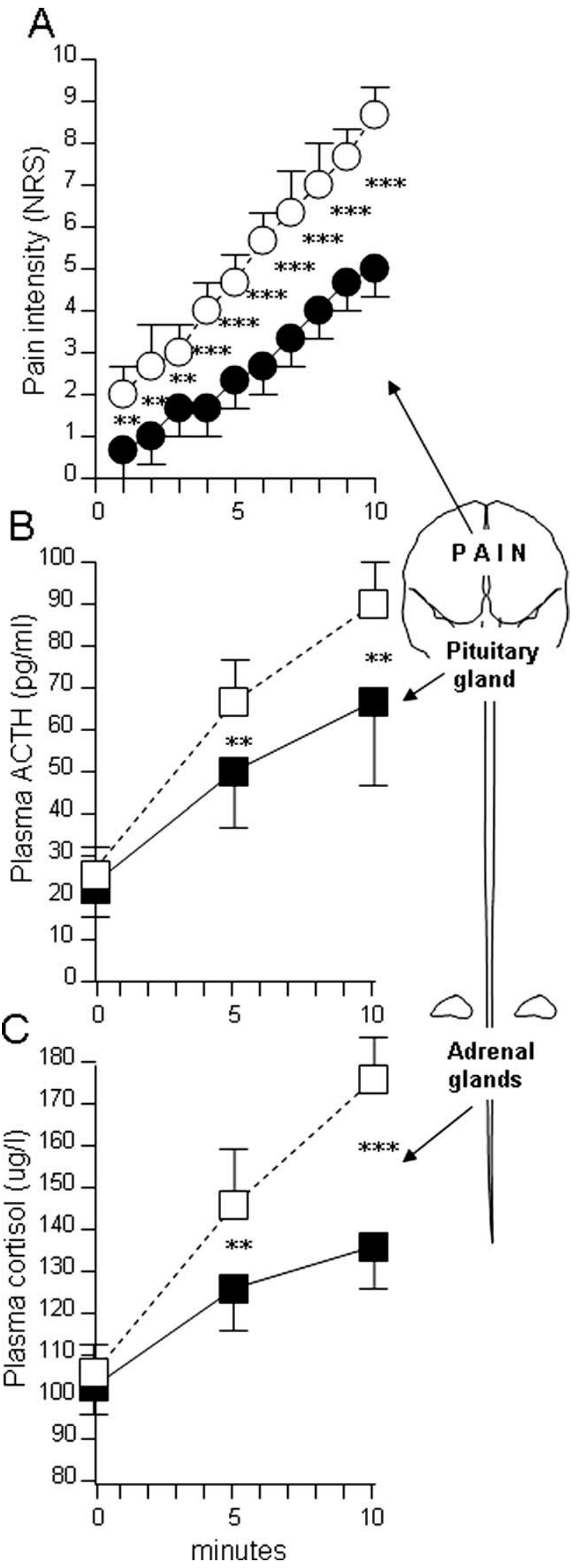

Figure 3. The natural history of pain $(\boldsymbol{A}), \mathrm{ACTH}(\boldsymbol{B})$, and cortisol $(\boldsymbol{C})$ in test 1 (black symbols) is compared with the nocebo condition of test 2 (white symbols), in which verbal suggestions of pain worsening were given. Note that, in the nocebo condition, there was a significant increase of both pain perception and $\mathrm{ACTH}$ and cortisol plasma concentrations. ${ }^{* *} p<0.01$; ${ }^{* * *} p<0.001$. 


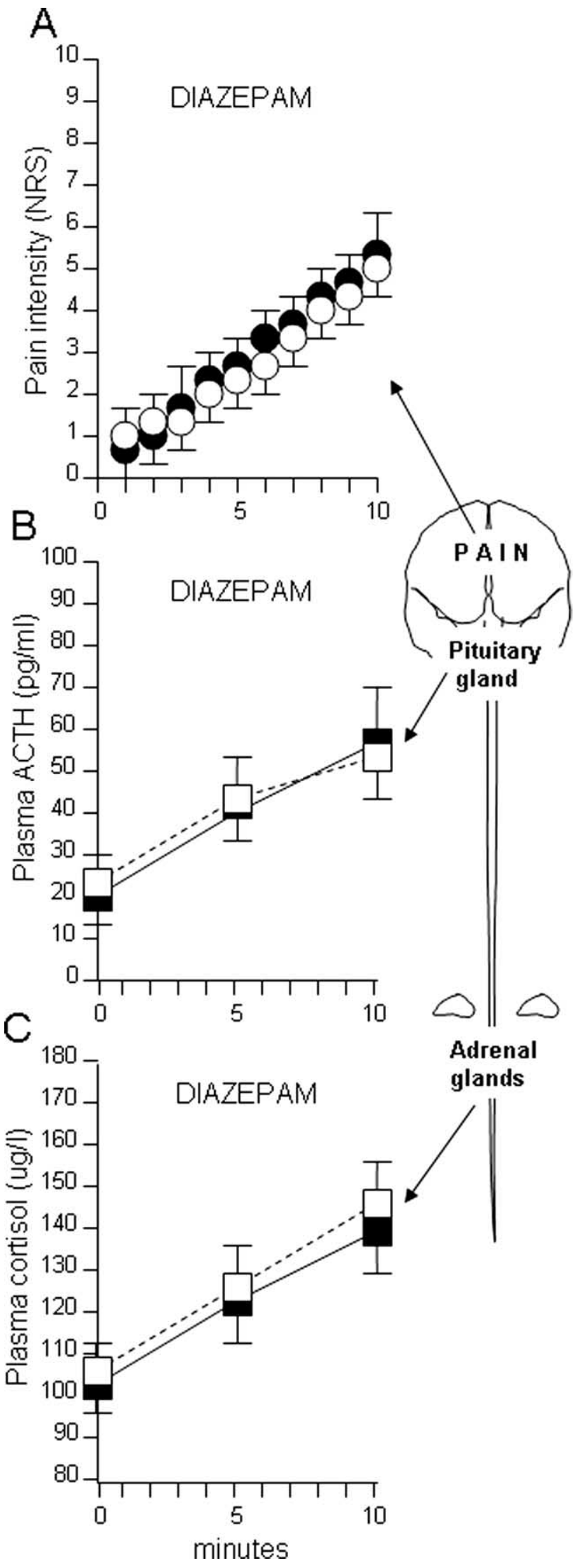

Figure 4. The effect of diazepam on basal pain increase $(\boldsymbol{A})$, basal ACTH increase $(\boldsymbol{B})$, and basal cortisol increase $(\boldsymbol{C})$ in test 1 (black symbols) is compared with diazepam in the nocebo condition of test 2 (white symbols). Note that diazepam suppressed both nocebo hyperalgesia and nocebo increase of ACTH and cortisol plasma concentrations. In fact, no difference was present between tests 1 and 2 . was $140.9 \pm 8.55$ and $174.1 \pm 14.48 \mu \mathrm{g} / \mathrm{L}$, respectively $\left(q_{(55)}=\right.$ $15.262 ; p<0.001)$.

An intergroup one-way ANOVA showed that neither diazepam nor proglumide had an analgesic effect in non-nocebo conditions. In fact, there was no significant difference in pain time course between diazepam in the non-nocebo condition (Fig. $4 \mathrm{~A}$, black circles) and the natural history of group 1 (Fig. 2 A). Likewise, there was no difference in the time course of pain intensity between proglumide in the non-nocebo condition (Fig. $5 A$, black circles) and the natural history of group 1 (Fig. $2 A$ ). In contrast, a significant decrease of pain occurred in the nocebo condition with both diazepam and proglumide compared with the drugfree nocebo condition of Figure $3 A$ (white circles). In fact, at the end of the 10 min test, pain rating was $5.16 \pm 0.57$ with diazepam and $5.58 \pm 0.9$ with proglumide compared with $8.61 \pm 0.96$ in the drug-free condition of group $2\left(F_{(1,23)}=116.6, p<0.001\right.$; $F_{(1,23)}=66.07, p<0.001$, respectively). Therefore, whereas both diazepam and proglumide were ineffective as analgesics on basal pain, they proved to be effective in reducing the nocebo hyperalgesic component. In other words, both drugs affected only the nocebo component of pain.

The intergroup analysis of the hormonal responses produced similar results for diazepam but not for proglumide. In fact, there was no significant difference in ACTH-cortisol time course between diazepam in the non-nocebo condition (Fig. $4 B$, $C$, black squares) and the natural history of group 1 (Fig. $2 B, C$ ). In contrast, a significant decrease of both ACTH and cortisol plasma concentrations occurred in the nocebo condition with diazepam compared with the drug-free nocebo condition of Figure 3, $B$ and $C$ (white squares). In fact, at the end of the $10 \mathrm{~min}$ test, ACTH plasma concentration was $54.75 \pm 10.01 \mathrm{pg} / \mathrm{ml}$ with diazepam compared with $86.69 \pm 8.45 \mathrm{pg} / \mathrm{ml}$ in the drug-free condition of group $2\left(F_{(1,23)}=74.74 ; p<0.001\right)$, and cortisol concentration was $142 \pm 8.31 \mu \mathrm{g} / \mathrm{L}$ compared with $174.2 \pm 12.46 \mu \mathrm{g} / \mathrm{L}$ in group $2\left(F_{(1,23)}=56.74 ; p<0.001\right)$. In contrast to the hormonal effects of diazepam, proglumide induced no effects on ACTH and cortisol, in neither the non-nocebo nor nocebo condition, as shown by no significant differences in the intergroup analysis between groups 1,2 , and 4 .

Finally, a correlation analysis between pain ratings and hormone plasma concentrations did not show any significant effect in the non-nocebo and the nocebo conditions.

\section{Discussion}

Most of placebo research in recent times has focused on placebo effects in pain and Parkinson's disease. In the first case, there are now several converging lines of evidence indicating that placeboinduced expectations of analgesia activate the endogenous opioid systems in some circumstances (Benedetti et al., 2005; Colloca and Benedetti, 2005; Hoffman et al., 2005; Zubieta et al., 2005). In the second case, dopamine release in the striatum seems to play an important role (de la Fuente-Fernandez et al., 2001), and the placebo response in Parkinson patients is associated with neuronal changes in the subthalamic nucleus (Benedetti et al., 2004).

In contrast, the study of the nocebo effect has not been carefully investigated, although some attempts to analyze its underlying neurobiological mechanisms have been performed (Benedetti et al., 1997, 2003; Johansen et al., 2003). For example, we tried to assess the role of CCK in nocebo hyperalgesia in postoperative patients by using a neuropharmacological approach with the CCK antagonist proglumide (Benedetti et al., 1997). Although in our previous study we showed a blockade of nocebo hyperalgesia by proglumide, the clinical experimental 


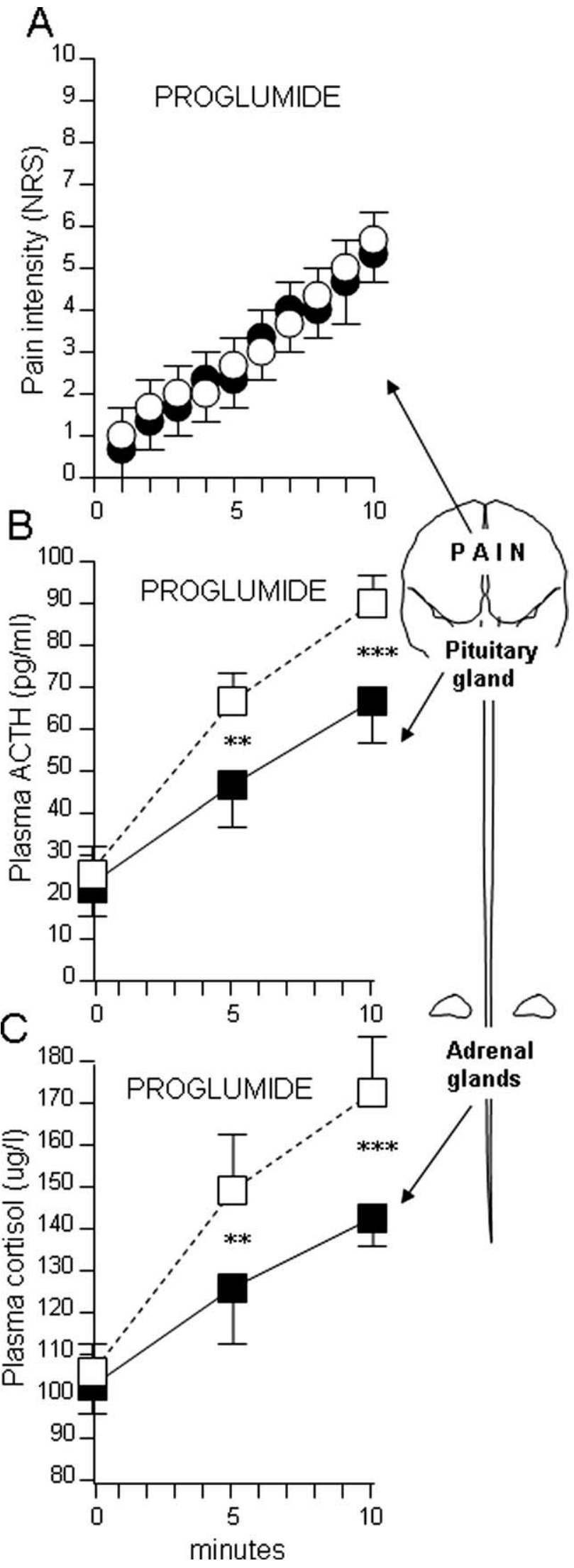

Figure 5. The effect of proglumide on basal pain increase $(\boldsymbol{A})$, basal ACTH increase $(\boldsymbol{B})$, and basal cortisol increase $(\boldsymbol{C})$ in test 1 (black symbols) is compared with proglumide in the nocebo condition of test 2 (white symbols). Note that, whereas proglumide suppressed nocebo hyperalgesia, it was ineffective in suppressing the nocebo increase of ACTH and cortisol plasma concentrations. ${ }^{* *} p<0.01 ;{ }^{* * *} p<0.001$. setting presented many ethical limitations. Therefore, in the present study, we addressed several unanswered questions of the study by Benedetti et al. (1997) by performing a careful analysis of the effects of proglumide on both pain and HPA axis in different nocebo and non-nocebo conditions and, moreover, by comparing the effects of proglumide with those of diazepam, a widely known anti-anxiety drug.

First of all, some methodological considerations and some limitations of the present study are worthy of discussion. We studied ACTH and cortisol because several studies have shown that the plasma concentrations of these hormones are sensitive to a number of stressors (Dickerson and Kemeny, 2004), including experimental ischemic arm pain (Gullner et al., 1982; Johansen et al., 2003). In particular, a short-latency response of cortisol has been shown in ischemic pain (Johansen et al., 2003), thus making our 10-min-long experimental pain a good model for HPA analysis. We used a neuropharmacological approach in humans with a nonspecific CCK antagonist for at least two reasons. First, the neuropharmacological approach to placebo analgesia with the opioid antagonist naloxone has been crucial to the understanding of the neurobiology of the placebo analgesic effect (Levine et al., 1978; Grevert et al., 1983; Levine and Gordon, 1984; Benedetti, 1996; Amanzio and Benedetti, 1999; Benedetti et al., 1999). In fact, these early pharmacological studies have been confirmed recently by several brain imaging studies, which basically show a similarity between narcotics and placebos in the activation of different brain regions (Petrovic et al., 2002) and the in vivo activation of the $\mu$-opioid receptors following a placebo procedure (Zubieta et al., 2005). Therefore, the neuropharmacological study of placebo/nocebo phenomena with agonist and antagonist drugs in humans appears to be a reliable experimental approach that gives important information. The second reason why we decided to use the pharmacological approach with proglumide is that we were not so much interested in the involvement of specific CCK receptors but rather in studying CCK from a general point of view. In this sense, proglumide has proven to be useful in investigating placebo analgesia (Benedetti et al., 1995; Benedetti, 1996; Colloca and Benedetti, 2005).

Although proglumide is a weak CCK antagonist, its anti-CCK action in the brain has been demonstrated. There is behavioral and electrophysiological evidence that CCK is blocked by proglumide in the brain (Chiodo and Bunney, 1983; Suberg et al., 1985; Watkins et al., 1985a,b). The results obtained in humans on opioid potentiation by proglumide (Price et al., 1985; Lavigne et al., 1989; Benedetti et al., 1995; Benedetti, 1996) are in keeping with the potentiation of morphine analgesia by the CCK-A antagonist devazepide in the rat (Dourish et al., 1988) and with the results obtained in animal studies using CCK-B antagonists (Wiesenfeld-Hallin et al., 1990; Maldonado et al., 1993; Noble et al., 1993; Valverde et al., 1994; Xu et al., 1994; Andre et al., 2005). Proglumide has also been reported to block the anxiogenic effects of the tetrapeptide CCK-4 and caerulein, a CCK- 8 agonist, indicating an anti-CCK action in the CNS at the level of affective mechanisms (Harro et al., 1990; Harro and Vasar, 1991; Van Megen et al., 1994).

By taking into consideration the limitations discussed above, the present study suggests that the nocebo hyperalgesic counterpart of the placebo/nocebo phenomenon is mediated by CCK. In particular, it suggests that the CCK antagonist proglumide does not act on the nocebo-induced anxiety but rather on anxietyinduced hyperalgesia. In fact, whereas diazepam reduced both HPA activation and pain perception, proglumide affected pain but not the HPA axis. The most plausible explanation of our 
Nocebo

\section{suggestions}

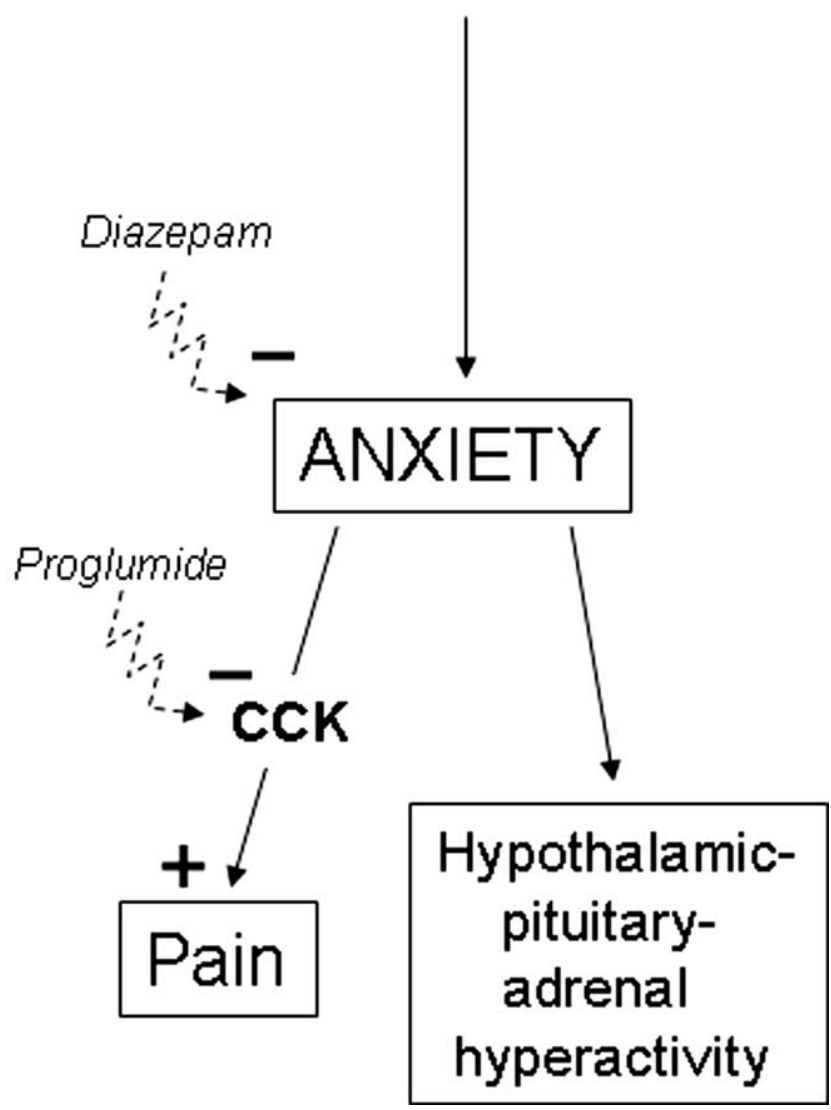

Figure 6. Model to explain the findings of the present study. Nocebo-induced anxiety affects both the HPA axis and pain mechanisms. The link between anxiety and pain is represented by CCK, which has a facilitating effect on pain. Benzodiazepines, like diazepam, can block anxiety, thus preventing both HPA hyperactivity and hyperalgesia. CCKantagonists, such as proglumide, only block the CCKergic anxiety-pain link. Therefore, CCK antagonists do not inhibit pain per se but rather the anxiety-pain link.

findings is shown in Figure 6. The reduction of both pain and HPA hyperactivity by diazepam can be explained by its anxiolytic effect, thus affecting nocebo-induced anxiety. It should be noted, however, that nonspecific effects of diazepam, e.g., on arousal, cannot be ruled out completely. In this regard, it will be interesting to use measures of anxiety in future studies. In contrast, proglumide was likely to affect only the CCK-mediated link between anxiety and pain. Although we did not test naloxone in the present study, the involvement of endogenous opioids in the blockade of nocebo hyperalgesia seems to be unlikely, as shown by the ineffectiveness of naloxone in our previous study (Benedetti et al., 1997). This CCK link between anxiety and pain is in agreement with studies in rodents in which more selective CCK antagonists were used. For example, a recent study showed that CI-988, a specific CCK-B receptor antagonist, blocked anxiety-induced hyperalgesia, which indicates a biochemical link between anxiety and pain that is mediated by CCK-B receptors (Andre et al., 2005).

In recent years, there has been accumulating evidence that CCK acts as a neuromodulator of different functions, such as pain and anxiety, although the exact mechanisms are still unclear. CCK is found in the brain as an octapeptide (CCK-8) and has

\section{Diazepam}
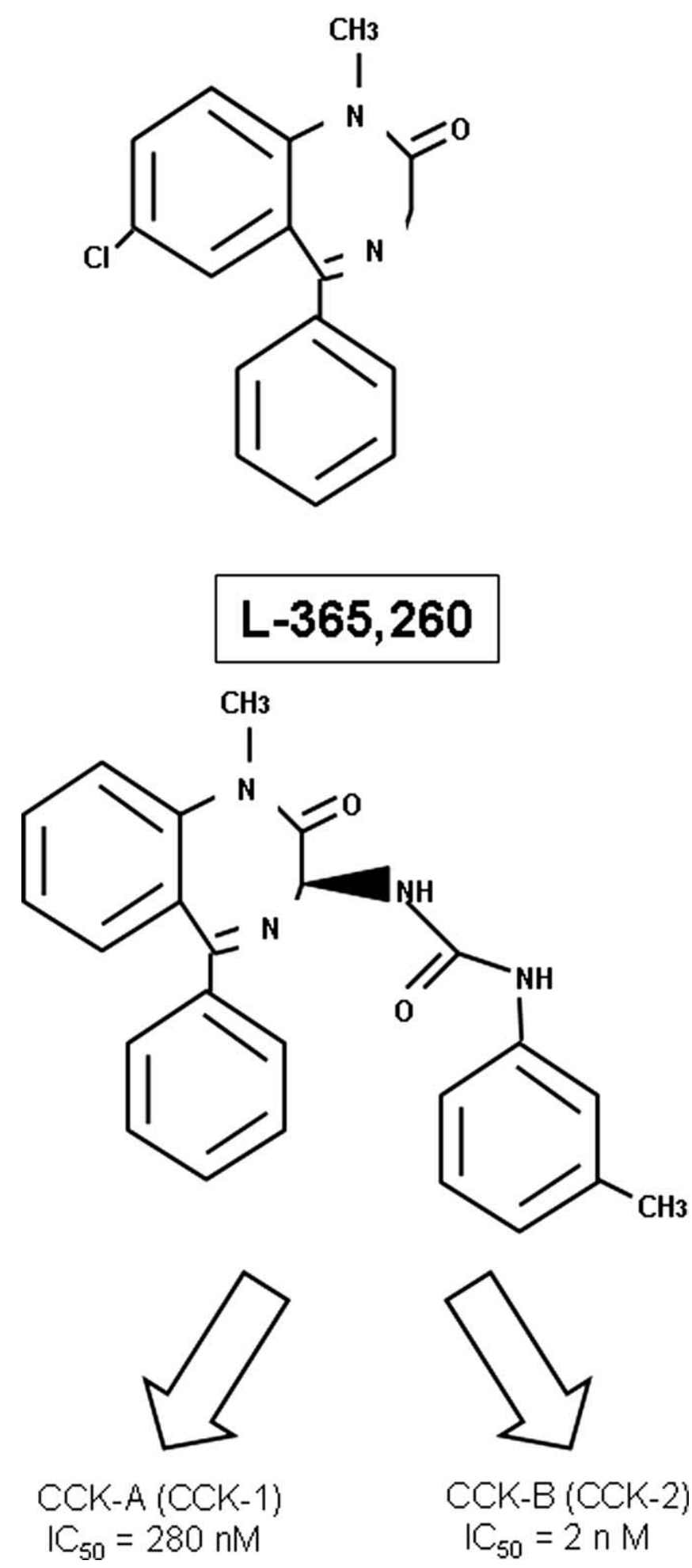

Figure 7. The structural formula of the anxiolytic drug diazepam, one of the most used benzodiazepines, is similar to L-365,260, a benzodiazepine-based CCK antagonist, thus suggesting similar mechanisms of action of benzodiazepines and CCK antagonists. Note the higher binding affinity of L-365,260 for CCK-B receptors compared with CCK-A receptors, expressed as the concentration required to inhibit by $50 \%$ the specific binding of ${ }^{125} \mathrm{I}$-Bolton-Hunter CCK-8 $\left(\mathrm{IC}_{50}\right)$. 
many functions, ranging from pain modulation to anxiety (Vanderhaegen et al., 1975; Beinfeld, 1983; Baber et al., 1989; Crawley and Corwin, 1994; Hebb et al., 2005). The distribution of CCK in the brain matches that of the opioid peptides at both the spinal and supraspinal level (Stengaard-Pedersen and Larsson, 1981; Gall et al., 1987; Gibbins et al., 1987), suggesting a close interaction between the two neuropeptides.

The involvement of CCK in both pain modulation and anxiety is particularly relevant to the present study. Interestingly, it is worth noting that some CCK-B receptor antagonists, such as L-365,260 [3S(-) [N'-2,3-dehydro-1-methyl-2-oxo5-phenyl$1 H$-1,4-benzodiazepin-3-yl]-1 $H$-indole-2-carboxamide], have a benzodiazepine-based chemical structure that is similar to the anxiolytic drug diazepam (Fig. 7), thus suggesting a similarity of action of CCK antagonists and benzodiazepines. In this regard, the recent work by Andre et al. (2005) in the rat shows that CCK-B receptor blockade antagonizes anxiety-induced hyperalgesia. This suggests a CCKergic link between anxiety and hyperalgesia, whereby anxiety-activated CCK has a facilitating action on pain. Our present study confirms these effects in humans and suggests that our nocebo procedure induced anticipatory anxiety about the impending pain.

It should also be stressed that the anti-CCK action of proglumide did not show any real analgesic effect, because the basal pain increase of the natural history group was unaffected. In other words, proglumide was effective only on the nocebo component of pain, that is, only on the anxiety-induced hyperalgesia. Therefore, CCK antagonists appear to be useful not so much as analgesics but rather as drugs suppressing the hyperalgesia induced by anxiety. Interestingly, the suppressing action of proglumide on nocebo (anxiety)-induced hyperalgesia was similar to that of diazepam, which further confirms the specific action of both benzodiazepines and CCK antagonists on anxiety-related pain.

The discrepancy between stress-induced hyperalgesia and stress-induced analgesia may be only apparent, because the nature of the stressor is likely to play a central role. In fact, whereas hyperalgesia may occur when the anticipatory anxiety is about the pain itself (Benedetti et al., 1997; Sawamoto et al., 2000; Koyama et al., 2005; Keltner et al., 2006), analgesia may occur when anxiety is about a stressor that shifts the attention from the pain (Willer and Albe-Fessard, 1980; Terman et al., 1986). The present study further suggests that there are two different pathways for anxiety-induced HPA hyperactivity and hyperalgesia (Fig. 6).

In conclusion, the hyperalgesic nocebo effect appears to be attributable to complex biochemical and neuroendocrine mechanisms that link anxiety to pain. On the one hand, nocebo suggestions induce anticipatory anxiety and thus the hyperactivity of the HPA axis. On the other hand, the nocebo-induced anxiety seems to activate CCKergic systems, which, in turn, facilitate pain transmission. Therefore, the placebo/nocebo phenomenon, with its opposite modulating effects on pain, is a very interesting model to understand the reciprocal and antagonist action of the opioidergic and CCKergic systems that are involved in the intricate mechanisms linking cognition and emotions to pain.

\section{References}

Amanzio M, Benedetti F (1999) Neuropharmacological dissection of placebo analgesia: expectation-activated opioid systems versus conditioning-activated specific sub-systems. J Neurosci 19:484-494.

Andre J, Zeau B, Pohl M, Cesselin F, Benoliel J-J, Becker C (2005) Involvement of cholecystokininergic systems in anxiety-induced hyperalgesia in male rats: behavioral and biochemical studies. J Neurosci 25:7896-7904.
Baber NS, Dourish CT, Hill DR (1989) The role of CCK, caerulein, and CCK antagonists in nociception. Pain 39:307-328.

Beinfeld MC (1983) Cholecystokinin in the central nervous system: a minireview. Neuropeptides 3:411-427.

Benedetti F (1996) The opposite effects of the opiate antagonist naloxone and the cholecystokinin antagonist proglumide on placebo analgesia. Pain 64:535-543.

Benedetti F (1997) Cholecystokinin type A and type B receptors and their modulation of opioid analgesia. News Physiol Sci 12:263-268.

Benedetti F, Amanzio M, Maggi G (1995) Potentiation of placebo analgesia by proglumide. Lancet 346:1231.

Benedetti F, Amanzio M, Casadio C, Oliaro A, Maggi G (1997) Blockade of nocebo hyperalgesia by the cholecystokinin antagonist proglumide. Pain 71:135-140.

Benedetti F, Arduino C, Amanzio M (1999) Somatotopic activation of opioid systems by target-directed expectations of analgesia. J Neurosci 19:3639-3648.

Benedetti F, Pollo A, Lopiano L, Lanotte M, Vighetti S, Rainero I (2003) Conscious expectation and unconscious conditioning in analgesic; motor and hormonal placebo/nocebo responses. J Neurosci 23:4315-4323.

Benedetti F, Colloca L, Torre E, Lanotte M, Melcarne A, Pesare M, Bergamasco B, Lopiano L (2004) Placebo-responsive Parkinson patients show decreased activity in single neurons of subthalamic nucleus. Nat Neurosci 7:587-588.

Benedetti F, Mayberg HS, Wager TD, Stohler CS, Zubieta JK (2005) Neurobiological mechanisms of the placebo effect. J Neurosci 25:10390-10402.

Chiodo LA, Bunney BS (1983) Proglumide: selective antagonism of excitatory effects of cholecystokinin in central nervous system. Science 219:1449-1451.

Colloca L, Benedetti F (2005) Placebos and painkillers: is mind as real as matter? Nat Rev Neurosci 6:545-552.

Crawley JN, Corwin RL (1994) Biological actions of cholecystokinin. Peptides 15:731-755.

de la Fuente-Fernandez R, Ruth TJ, Sossi V, Schulzer M, Calne DB, Stoessl AJ (2001) Expectation and dopamine release: mechanism of the placebo effect in Parkinson's disease. Science 293:1164-1166.

Dickerson SS, Kemeny MME (2004) Acute stressors and cortisol responses: a theoretical integration and synthesis of laboratory research. Psychol Bull 130:355-391.

Dourish CT, Hawley D, Iversen SD (1988) Enhancement of morphine analgesia and prevention of morphine tolerance in the rat by the cholecystokinin antagonis L-364,718. Eur J Pharmacol 147:469-472.

Gall C, Lauterborn J, Burks D, Seroogy K (1987) Co-localization of enkephalin and cholecystokinin in discrete areas of the rat brain. Brain Res 403:403-408.

Gibbins IL, Furness JB, Costa M (1987) Pathway-specific patterns of coexistence of substance $\mathrm{P}$, calcitonin gene-related peptide, cholecystokinin and dynorphin in neurons of the dorsal root ganglia of the guinea pig. Cell Tisue Res 248:417-437.

Grevert P, Albert LH, Goldstein A (1983) Partial antagonism of placebo analgesia by naloxone. Pain 16:129-143.

Gullner H-G, Nicholson WE, Wilson MG, Bartter FC, Orth DN (1982) The response of plasma immunoreactive adrenocorticotropin, betaendorphin/beta-lipotropin, gamma-lipotropin and cortisol to experimentally induced pain in normal human subjects. Clin Sci 63:397-400.

Harro J, Vasar E (1991) Evidence that CCK-B receptors mediate the regulation of exploratory behaviour in the rat. Eur J Pharmacol 193:379-381.

Harro J, Pold M, Vasar E (1990) Anxiogenic-like action of caerulein, a CCK-8 receptor agonist in the mouse: influence of acute and subchronic diazepam treatment. Naunyn Schmiedebergs Arch Pharmacol 341:62-67.

Hebb ALO, Poulin J-F, Roach SP, Zacharko RM, Drolet G (2005) Cholecystokinin and endogenous opioid peptides: interactive influence on pain, cognition, and emotion. Prog Neuropsychopharmacol Biol Psychiatry 29:1225-1238.

Hoffman GA, Harrington A, Fields HL (2005) Pain and the placebo: what we have learned. Persp Biol Med 48:248-265.

Johansen O, Brox J, Flaten MA (2003) Placebo and nocebo responses, cortisol, and circulating beta-endorphin. Psychosom Med 65:786-790.

Keltner JR, Furst A, Fan C, Redfern R, Inglis B, Fields HL (2006) Isolating the modulatory effect of expectation on pain transmission: a functional magnetic resonance imaging study. J Neurosci 26:4437-4443. 
Kong J, Gollub RL, Rosman IS, Webb JM, Vangel MG, Kirsch I, Kaptchuk TJ (2006) Brain activity associated with expectancy-enhanced placebo analgesia as measured by functional magnetic resonance imaging. J Neurosci 26:381-388.

Koyama T, McHaffie JG, Laurienti PJ, Coghill RC (2005) The subjective experience of pain: where expectations become reality. Proc Natl Acad Sci USA 102:12950-12955.

Lavigne GJ, Hargreaves KM, Schmidt EA, Dionne RA (1989) Proglumide potentiates morphine analgesia for acute postsurgical pain. Clin Pharmacol Ther 45:666-673.

Levine JD, Gordon NC (1984) Influence of the method of drug administration on analgesic response. Nature 312:755-756.

Levine JD, Gordon NC, Fields HL (1978) The mechanisms of placebo analgesia. Lancet 2:654-657.

Liddle G (1974) The adrenal cortex. In: Textbook of endocrinology (Williams RH, ed), Ed 5. Philadelphia: Saunders.

Maldonado R, Derrien M, Noble F, Roques BP (1993) Association of a peptidase inhibitor and a CCK-B antagonist strongly potentiates antinociception mediated by endogenous enkephalins. NeuroReport 7:947-950.

Nattero G, De Lorenzo C, Biale L, Allais G, Torre E, Ancona M (1989) Psychological aspects of weekend headache sufferers in comparison with migraine patients. Headache 29:93-99.

Noble F, Derrien M, Roques BP (1993) Modulation of opioid antinociception by CCK at the supraspinal level: evidence of regulatory mechanisms between CCK and enkephalin systems in the control of pain. Br J Pharmacol 109:1064-1070.

Noble F, Wank SA, Crawley JN, Bradwejn J, Seroogy KB, Hamon M, Roques BP (1999) International Union of Pharmacology. XXI. Structure, distribution, and functions of cholecystokinin receptors. Pharmacol Rev 51:745-781.

Petrovic P, Kalso E, Petersson KM, Ingvar M (2002) Placebo and opioid analgesia: imaging a shared neuronal network. Science 295:1737-1740.

Petrovic P, Dietrich T, Fransson P, Andersson J, Carlsson K, Ingvar M (2005) Placebo in emotional processing: induced expectations of anxiety relief activate a generalized modulatory network. Neuron 46:957-969.

Price DD, Von der Gruen A, Miller J, Rafii A, Price C (1985) Potentiation of systemic morphine analgesia in humans by proglumide, a cholecystokinin antagonist. Anesth Analg 64:801-806.

Price DD, Chung SK, Robinson ME (2005) Conditioning, expectation and desire for relief in placebo analgesia. Sem Pain Med 3:15-21.

Rainero I, Valfre W, Savi L, Gentile S, Pinessi L, Gianotti L, Arvat E, Ghigo E, Del Rizzo P, Calvelli P, Limone P (2001) Neuroendocrine effects of subcutaneous sumatriptan in patients with migraine. J Endocrinol Invest $24: 310-315$.

Sawamoto N, Honda M, Okada T, Hanakawa T, Kanda M, Fukuyama H, Konishi J, Shibasaki H (2000) Expectation of pain enhances responses to nonpaiful somatosensory stimulation in the anterior cingulate cortex and parietal operculum/posterior insula: an event-related functional magnetic resonance imaging study. J Neurosci 20:7438-7445.

Spielberg CD, Gorsuch RL, Luschenne RE (1980) STAI. Questionario di autovalutazione per l'ansia di stato e di tratto. Florence, Italy: Organizzazioni Speciali.

Stengaard-Pedersen K, Larsson LI (1981) Localization and opiate receptor binding of enkephalin, CCK and ACTH/beta-endorphin in the rat central nervous system. Peptides 1:3-19.

Suberg SN, Culhane ES, Carstens E, Watkins LR (1985) Behavioral and electrophysiological investigations of opiate/cholecystokinin interactions. In: Advances in pain research and therapy, Vol 9 (Fields HL, Dubner R, Cervero F, eds), pp 541-553. New York: Raven.

Terman GW, Morgan MJ, Liebeskind JC (1986) Opioid and non-opioid stress analgesia from cold water swim: importance of stress severity. Brain Res 372:167-171.

Valverde O, Maldonado R, Fournie-Zaliski MC, Roques BP (1994) Cholecystokinin B antagonists strongly potentiate antinociception mediated by endogenous enkephalins. J Pharmacol Exp Ther 270:77-88.

Vanderhaegen JJ, Signeau JC, Gepts W (1975) New peptide in the vertebrate CNS reacting with antigastrin antibodies. Nature 257:604-605.

Van Megen HJGM, Den Boer JA, Westenberg HGM (1994) On the significance of cholecystokinin receptors in panic disorder. Prog Neuropsychopharmacol Biol Psychiatry 18:1235-1246.

Wager TD, Rilling JK, Smith EE, Sokolik A, Casey KL, Davidson RJ, Kosslyn SM, Rose RM, Cohen JD (2004) Placebo-induced changes in fMRI in the anticipation and experience of pain. Science 303:1162-1166.

Wager TD, Matre D, Casey KL (2006) Placebo effects in laser-evoked pain potentials. Brain Behav Immunity 20:219-230.

Watkins LR, Kinscheck IB, Mayer DJ (1985a) Potentiation of morphine analgesia by the cholecystokinin antagonist proglumide. Brain Res 327:169-180.

Watkins LR, Kinscheck IB, Kaufmann EFS, Miller J, Frenk H, Mayer DJ (1985b) Cholecystokinin antagonists selectively potentiate analgesia induced by endogenous opiates. Brain Res 327:181-190.

Wiesenfeld-Hallin Z, Xu X-J, Hyghes J, Horwell DC, Hokfelt T (1990) PD 134308 , a selective antagonist of cholecystokin type $\mathrm{B}$ receptor, enhances the analgesic effect of morphine and synergistically interacts with intrathecal galanin to depress spinal nociceptive reflexes. Proc Natl Acad Sci USA 87:7105-7109.

Willer JC, Albe-Fessard D (1980) Electrophysiological evidence for a release of endogenous opiates in stress-induced analgesia in man. Brain Res 198:419-426.

Xu X-J, Hokfelt T, Hughes J, Wiesenfeld-Hallin Z (1994) The CCK-B antagonist CI-988 enhances the reflex-depressive effect of morphine in axotomized rats. NeuroReport 5:718-720.

Zubieta JK, Bueller JA, Jackson LR, Scott DJ, Xu Y, Koeppe RA, Nichols TE, Stohler CS (2005) Placebo effects mediated by endogenous opioid neurotransmission and $\mu$-opioid receptors. J Neurosci 25:7754-7762. 